\title{
The genetic control of phenformin 4-hydroxylation
}

\author{
R R SHAH*, D A P EVANS $\dagger$, N S OATES, J R IDLE, AND R L SMITH \\ From the Department of Pharmacology, St Mary's Hospital Medical School, Norfolk Place, London W2 \\ 1PG; and the Department of Medicine C123, Riyadh Military Hospital, PO Box 7897, Riyadh 11159, \\ Kingdom of Saudi Arabia.
}

SUMmaRY Previously published results of phenformin 4-hydroxylation in 195 unrelated white British volunteers and 87 family members of 27 randomly selected probands have been subjected to genetic analysis. The results clearly show that about $9 \%$ of this population has a genetically determined defect in carrying out this oxidation reaction. The character for the defect is inherited in a Mendelian autosomal recessive fashion. The polymorphism shows a substantial degree of dominance.

A polymorphism in the alicyclic 4-hydroxylation of the hypotensive drug debrisoquine has been described. ${ }^{1}$ The study of selected families has indicated that poor hydroxylators of debrisoquine are autosomal Mendelian recessives, while the extensive hydroxylators are dominant. ${ }^{2}$

Phenformin is a biguanide that was formerly used as an oral hypoglycaemic agent in maturity onset diabetes. It is rapidly absorbed in man and metabolised exclusively by $p$-hydroxylation to a single metabolite, 4-hydroxy-phenformin. ${ }^{3}$ The unchanged drug and its metabolite are cleared from the blood virtually exclusively by the kidneys. About twothirds of an oral dose is excreted in the urine within eight hours as the unchanged drug plus its metabolite.

The purpose of the present work was to ascertain whether or not the hydroxylation of phenformin was controlled by a genetic polymorphism.

The study was approved by the Ethics Committee of St Mary's Hospital, London, and every participant gave his or her fully informed consent.

\section{Methods}

VOLUNTEERS

A total of 195 unrelated volunteers participated in the study. These were recruited from the staff and students of St Mary's Hospital and Medical School. More than a week later, 51 of these 195 volunteers, selected at random, were studied again. A total of 87 close relatives of 27 of these 51 volunteers, again selected at random, also participated in the study.

*Present address: Department of Cardiology. King Fahad General Hospital, PO Box 204, Al Baha, Kingdom of Saudi Arabia.

Received for publication 3 April 1984.

Accepted for publication 23 November 1984.
All of the volunteers and their close relatives were in good general health.

\section{EXPERIMENTAL PROCEDURE}

Each subject was asked to swallow a single $50 \mathrm{mg}$ dose of conventionally formulated phenformin (Dibotin ${ }^{\circledR}$, Sterling Winthrop Laboratories, Guildford, UK) after an overnight fast. No other medications were allowed either before or during the study. A bulked 0 to 8 hour urine sample was collected after dosing, and after recording the total volume of urine voided an aliquot sample was stored at $-20^{\circ} \mathrm{C}$ for later analysis.

\section{ANALYSIS OF URINE}

On analysis, each urine sample was allowed to thaw at room temperature and the concentrations of phenformin and 4-hydroxy-phenformin determined. The details of the analytical method are described elsewhere. $^{4}$

From the urinary excretion of unchanged drug and 4-hydroxy-phenformin, an index of its oxidation, termed the phenformin ratio (PR), was derived as follows:

$$
\begin{gathered}
\mathrm{PR}=\frac{\% \text { oral dose excreted as phenformin }}{\% \text { oral dose excreted as 4-hydroxy- }} \begin{array}{c}
\text { in the } \\
\text { phenformin }
\end{array} \\
\begin{array}{c}
0 \text { to } 8 \\
\text { hour } \\
\text { urine. }
\end{array}
\end{gathered}
$$

This ratio is entirely analogous to the 'metabolic ratio' used in the studies on the oxidation of debrisoquine. This index not only allows estimation of drug oxidation capacity but it also avoids the complications arising from differences in total urinary recovery of drug related products. 


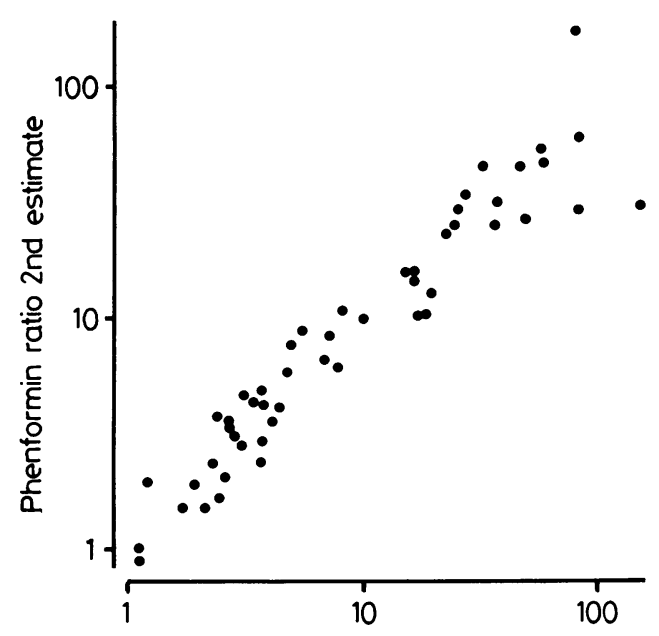

Phenformin ratio 1st estimate

FIG 1 Repeatability of the phenformin ratio in 51 subjects. (Spearman rank correlation, $r_{s}=0.97$ ).

\section{Results}

The 195 volunteers included 72 males and 123 females. The mean (and ranges) of their ages, weights, and heights were 22.3 (18 to 52 ) years, 63.4 (41 to 146) $\mathrm{kg}$, and 170.5 (152 to 198$) \mathrm{cm}$, respectively. The urinary recovery of phenformin plus 4-hydroxy-phenformin varied from 9.8 to $89.6 \%$ of the ingested dose. There was also a marked interindividual variation in phenformin oxidation capacity as judged by the phenformin ratio which ranged from $0 \cdot 9$ to 184 . The details of the volunteers together with their corresponding urinary recoveries of phenformin and 4-hydroxyphenformin and phenformin oxidation capacity have previously been published. ${ }^{56}$

The repeatability experiment on 51 subjects where PR was measured on two separate occasions yielded a Spearman rank correlation, $r_{s}$, of 0.97 $(\mathrm{p}<0.0001)$ (fig 1).
The cumulative frequency distribution of PR in the population deviated significantly from a straight line on both untransformed and semilogarithmic $\overrightarrow{0}$ scales. ${ }^{5}$ The latter plot showed an inflection between $\frac{C}{0}$ PR values of 10 and 35 . The appearance of the histogram suggested a bimodal distribution with an $\overparen{\otimes}$ antimode at about $\mathrm{PR}=20$, separating those with extensive metabolic capacity $(P R<20)$ from those ${ }^{\infty}$ with impaired metabolic capacity (PR $>20)$. These $\vec{\circ}$ were considered to represent two phenotypes, desig- $\overrightarrow{\vec{H}}$ nated respectively EM (extensive metaboliser) and $\stackrel{\omega}{\sigma}$ PM (poor metaboliser). ${ }^{5}$

Evidence that the phenotype difference is not? related to age, weight, height, or total recovery of $N$ parent drug plus metabolite, nor to sex, smoking, or or alcohol consumption, is shown in tables 1 and 2 .

The 27 probands for the family studies had a

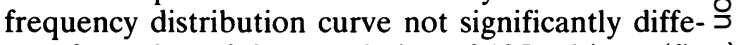
rent from that of the population of 195 subjects (fig $\vec{P}$ 2). Details of these families (27 probands plus 860 family members) have previously been published $\stackrel{0}{\circ}$ but without genetic analysis ${ }^{5}$ (fig 3 ). The index numbers used here are the same as in the previous $\overrightarrow{0}$ publication. One additional sib of the proband in 0 family 7 consented later to participate. She had a PR of 4.5 and is included in the calculations that follow.

If $p=$ frequency of the allele controlling extensive oxidation of phenformin and

$q=$ frequency of the allele controlling impaired $\frac{\Phi}{\Phi}$ oxidation of phenformin,

application of the Hardy-Weinberg equilibrium enables these frequencies to be calculated in the following way, on the assumption that poor metabolisers are autosomal Mendelian recessives. From the original population of 195 volunteers, 18 subjects had PR> 20; therefore $\mathrm{q}=V_{\frac{18}{195}}=0.304$ and $\mathrm{p}=3$ 0.696. Using the formula given by Emery ${ }^{7}$ the standard errors have been calculated as:

$$
\begin{aligned}
& q=0.304 \pm 0.034 \\
& p=0.696 \pm 0.026
\end{aligned}
$$

\begin{tabular}{|c|c|c|c|c|c|c|c|}
\hline Measurement & Phenotype & Number & Mean & $S D$ & Range & $t$ & $p$ \\
\hline Age (y) & $\begin{array}{l}\text { EM } \\
\text { PM }\end{array}$ & $\begin{array}{r}177 \\
18\end{array}$ & $\begin{array}{l}22 \cdot 3 \\
22 \cdot 9\end{array}$ & $\begin{array}{l}4 \cdot 9 \\
5 \cdot 2\end{array}$ & $\begin{array}{l}18-52 \\
19-38\end{array}$ & 0.53 & NS \\
\hline Body weight (kg) & $\begin{array}{l}\text { EM } \\
\text { PM }\end{array}$ & $\begin{array}{r}177 \\
18\end{array}$ & $\begin{array}{l}62 \cdot 7 \\
59 \cdot 9\end{array}$ & $\begin{array}{r}12 \cdot 5 \\
6 \cdot 1\end{array}$ & $\begin{array}{l}41-146 \\
53-74\end{array}$ & $1 \cdot 63$ & NS \\
\hline Height $(\mathrm{cm})$ & $\begin{array}{l}\text { EM } \\
\text { PM }\end{array}$ & $\begin{array}{r}177 \\
18\end{array}$ & $\begin{array}{l}170 \cdot 6 \\
169 \cdot 0\end{array}$ & $\begin{array}{l}8 \cdot 3 \\
7 \cdot 9\end{array}$ & $\begin{array}{l}152-198 \\
155-188\end{array}$ & 0.79 & NS \\
\hline $\begin{array}{l}\text { Urinary recovery of phenformin } \\
(\% \text { of ingested dose })\end{array}$ & $\begin{array}{l}\text { EM } \\
\text { PM }\end{array}$ & $\begin{array}{r}177 \\
18\end{array}$ & $\begin{array}{l}42 \cdot 3 \\
42 \cdot 1\end{array}$ & $\begin{array}{r}13 \cdot 9 \\
9 \cdot 7\end{array}$ & $\begin{array}{r}9 \cdot 8-89 \cdot 6 \\
16 \cdot 8-56 \cdot 4\end{array}$ & 0.08 & NS \\
\hline
\end{tabular}

TABLE 1 Relationship of PR phenotype to age, body weight, height, and urinary recovery of phenformin. 
TABLE 2 Relationship of PR phenotype to sex, smoking, and alcohol consumption.

\begin{tabular}{lrrrrr}
\hline Characteristic & \multicolumn{2}{c}{ Phenotype } & & \multirow{2}{*}{$\chi^{2}$} & $p$ \\
\cline { 2 - 3 } & $E M$ & $P M$ & & \\
\hline Male & 67 & 5 & $1 \cdot 0) 3$ & NS \\
Female & 110 & 13 & & \\
Smoker & 47 & 4 & $0 \cdot 31$ & NS \\
Non-smoker & 130 & 14 & & & NS \\
Alcohol consumer & 165 & 17 & 0 & \\
Alcohol non-consumer & 12 & 1 & & \\
\hline
\end{tabular}

These population estimates of allelle frequencies together with the data from the 25 complete two generation family units (two of the 27 families, Nos 14 and 15, had one parent each missing) were used to test firstly that the matings were random, and secondly the hypothesis that the PM phenotype was an autosomal recessive Mendelian character.

(1) The observed matings among the parents of different phenotypes have been compared to those expected by random mating (table 3 ). There was no significant difference between the observed and expected values $\left(\chi^{2}=3 \cdot 78 ; \mathrm{df}=\right.$ $2 ; \mathrm{p}>0 \cdot 2)$.

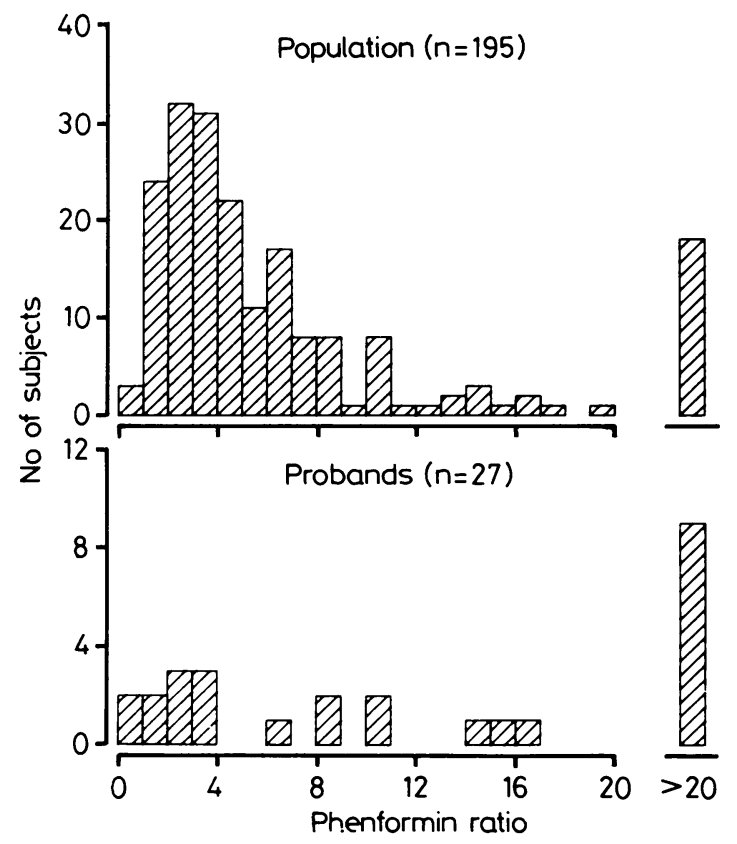

FIG 2 The frequency distribution of PR for 27 probands for the family study and the total population of 195 subjects. (The 195 subjects include the 27 probands.)

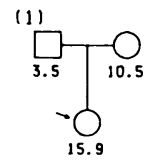

(6)

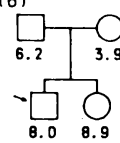

(11)

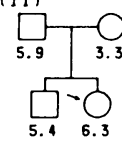

(16)

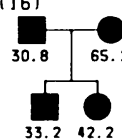

(21)

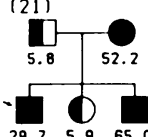

(26)

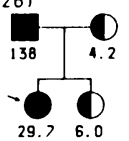

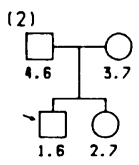

(7)

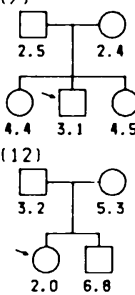

117)

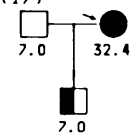

(22)

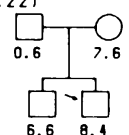

(2))
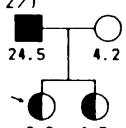

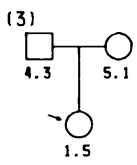

(8)

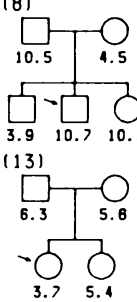

(18)

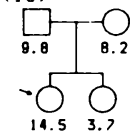

23)

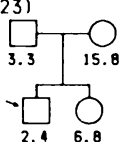

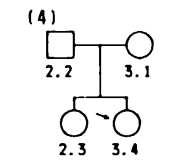

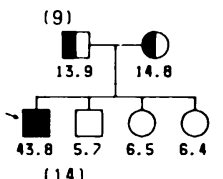

(14)

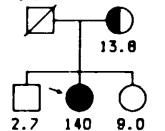

(19)

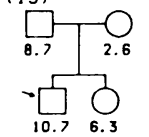

1241

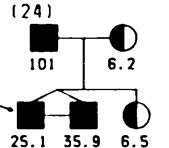

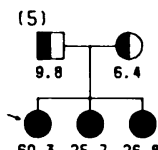

60.325 .726 .6 (10)

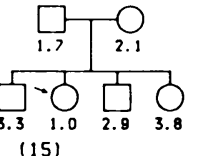

(15)

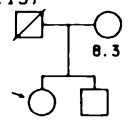

1.03 .4

120

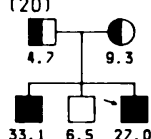

(25)

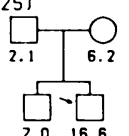

FIG 3 The pedigrees of 27

families in whom phenformin ratios have been determined as indicated by the values shown. $\square$ Male extensive metaboliser (genotype unknown).

$\bigcirc$ Female extensive metaboliser (genotype unknown).

Male poor metaboliser.

- Female poor metaboliser.

- Male extensive metaboliser identified as heterozygous*.

D Female extensive metaboliser identified as heterozygous*.

(*On the supposition that poor metabolisers are autosomal recessives.) $\square$ Dead.

$\rightarrow$ Proband. (Reproduced and adapted with permission from Oates NS, Shah RR, Idle JR, Smith RL. Genetic polymorphism of phenformin 4-hydroxylation in man. Clin Pharmacol Ther 1982;32: 81-9.) 
TABLE 3 Genetic inference from mating frequencies.

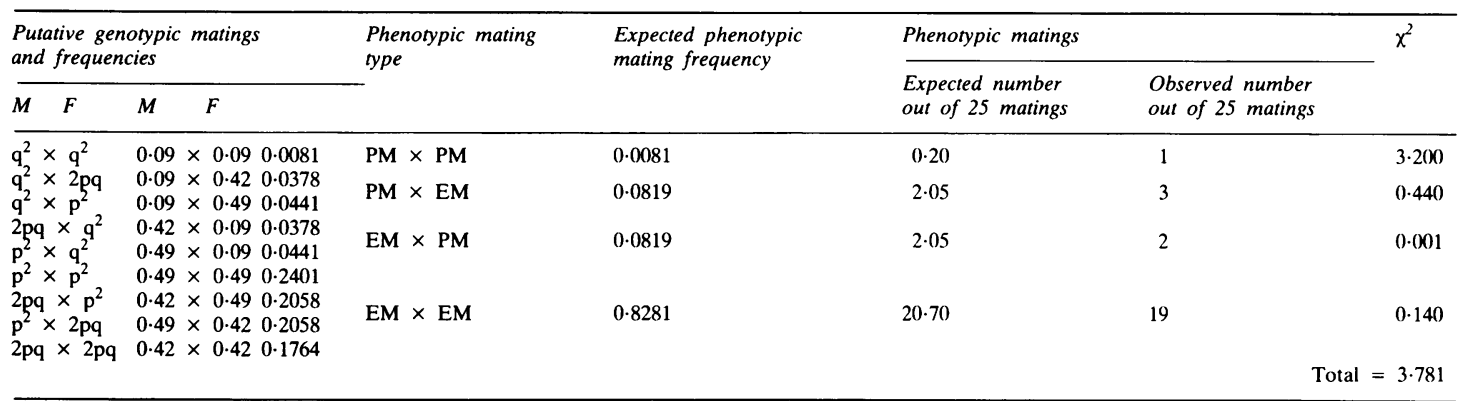

(2) The numbers of children of different phenotypes observed to be produced from each phenotypic mating have been compared to those expected (table 4). For this purpose the identical twins in family 24 were counted as one offspring. There was no significant difference between the observed and the expected values $\left(\chi^{2}=4.84 ; \mathrm{df}=2 ; \mathrm{p}>0.05\right)$.

When an alternative hypothesis, that is, that the EM phenotype is an autosomal Mendelian recessive, was tested in a similar manner there was a statistically significant difference between the observed and expected values rendering the hypothesis untenable.

In addition to the foregoing the following is to be noted.

(1) The identical twins in family 24 are both of the same oxidation phenotype.

(2) Observation of families 5, 9, and 20 exclude the possibility that poor metabolisers are autosomal $\frac{\text { o }}{\circ}$ Mendelian dominants.

(3) In family 16 both parents are poor metabolisers, and both offspring (of different sexes) are also poor metabolisers. This family supports the idea that poor metabolisers are Mendelian autosomal recessives.

(4) Families 16 and 24 exclude the possibilities that $\varnothing$ poor metabolisers are sex linked recessives or sex linked dominants.

The data were rendered approximately normal by transformations to $\log _{10}(P R+10)$. In this form the mean ratio for 16 heterozygotes was $1 \cdot 2376 \pm 0 \cdot 0854 \stackrel{2}{\not}$

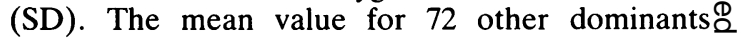
(excluding families 14 and 15 where the status of five $\vec{\overrightarrow{ }}$ dominants is in doubt) was $1 \cdot 1847 \pm 0 \cdot 0906$. The 3 difference between the means was highly significant $(t=7.7 ; \mathrm{p}<0.001)$ which indicates a substantialo degree of dominance.

TABLE 4 Genetic inference from offspring frequencies.

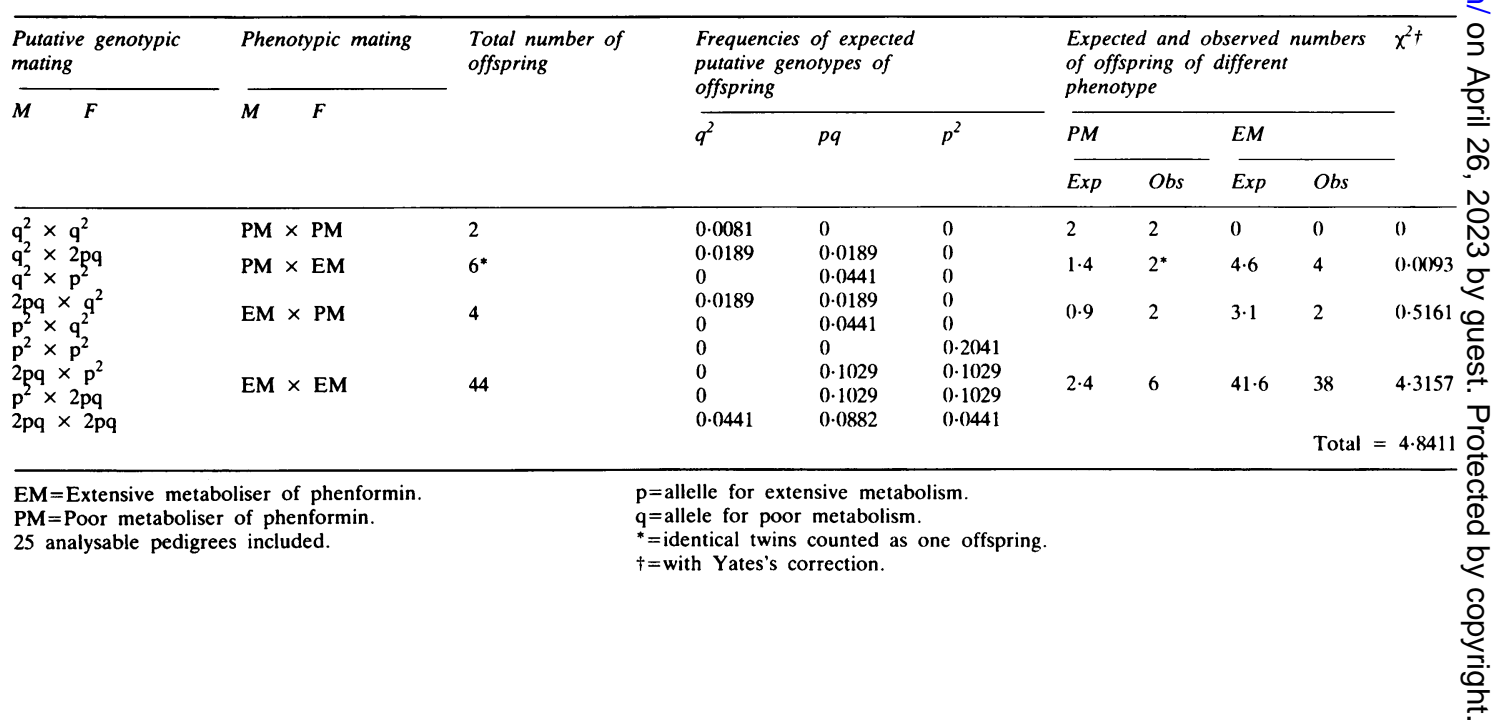


An attempt was made to estimate the dominance, using a method previously described, ${ }^{2}$ as follows:

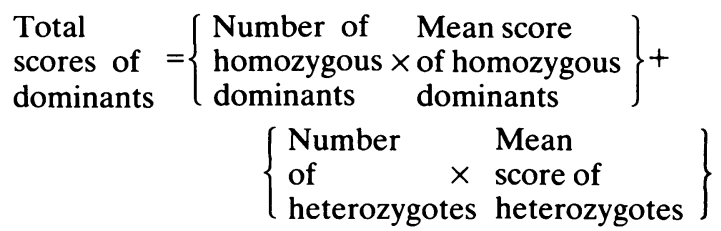

The number of homozygous dominants and of heterozygotes was found by applying the HardyWeinberg equilibrium. The frequency of poor metabolisers was higher in the family data than in the original population $\left(\chi^{2}=6.3\right)$ and so a new value of $q$ was computed as $\sqrt{\frac{21}{109}}=0.4389$. Consequently $\mathrm{p}^{2}$ $=0.3148$ and $2 \mathrm{pq}=0.4925$, and the mean score of homozygous dominants was $1 \cdot 1267$. The dominance (displacement of mean heterozygote score from the mid-point between the two homozygotes, expressed as a percentage of half the inter-homozygote distance) was $63 \%$.

\section{Discussion}

The results detailed above clearly demonstrate the genetic control of phenformin metabolism by 4hydroxylation in man by two alleles of major effect on one autosomal locus. It does not seem necessary to consider more than two alleles of major effect. The same data could be subjected to genetic analysis by the newer technique of complex segregation analysis ${ }^{8}$ which might reveal influences of alleles of minor effect and of environment.

The estimate of dominance can only be regarded as an approximation due to errors of measuring or computing the mean genotypic ratios on which its calculation is based. There can be no doubt, however, that the dominance effect is large, as can be shown for other substrates of the polymorphism, such as debrisoquine and sparteine by both the method used in this paper ${ }^{2}$ and by an alternative method of computation. ${ }^{9}$

Phenformin had worldwide popularity as an oral hypoglycaemic medication for maturity onset diabetes. Gradually it became clear that lactic acidosis, which often proved fatal, was occasionally associated with the use of the drug. ${ }^{10}$ It was noted that plasma phenformin concentrations were higher in persons developing this complication than in the general run of patients receiving similar dosages of the drug. ${ }^{11}$ In one study a correlation was demonstrated between plasma phenformin concentrations and plasma lactate concentrations in healthy volunteers. ${ }^{12}$ The drug fell into disrepute and was withdrawn from the UK market in 1983.

An individual idiosyncrasy, probably genetic, has been suggested for the predisposition to lactic acidosis. ${ }^{11} 13$ In support of this suggestion are the following.

(a) Healthy subjects with genetically impaired debrisoquine oxidation also have an impaired ability to hydroxylate phenformin. ${ }^{14}$

(b) After a single oral dose of $50 \mathrm{mg}$ phenformin to normal healthy persons of known debrisoquine oxidation phenotype, the poor metabolisers of debrisoquine developed higher plasma levels both of phenformin and of lactate. ${ }^{15}$

(c) Several patients who had developed lactic acidosis while on treatment with phenformin had an impaired ability to oxidise debrisoquine. ${ }^{16} 17$

Many drugs undergo metabolic oxidation and there is evidence of varying weight that this reaction for a number of these drugs is controlled by the alleles which control debrisoquine oxidation. The list includes sparteine, ${ }^{9}$ perhexiline, ${ }^{18}$ bufuralol, ${ }^{19}$ phenacetin, ${ }^{20}$ nortriptyline, ${ }^{21}$ metoprolol, ${ }^{22}$ and encainide. ${ }^{23}$ If the concordance of phenotypes for debrisoquine and phenformin can be shown for a sizeable population, then the identity of genetic control will be established.

However, if subjects are found in whom there is no concordance of phenotypes (for example, EM for debrisoquine and PM for phenformin) then, provided artefact can be excluded, a separate locus controlling oxidation may be found.

Not only is a thorough understanding of the genetic control of drug oxidation of value in elucidating the susceptibility to adverse reactions to medication, but it also holds promise to shed light on some spontaneous disorders. Associations have already been described between the extensive oxidation phenotype for debrisoquine and two conditions, hepatocellular carcinoma of the liver in Nigeria ${ }^{24}$ and interstitial endemic nephropathy in Bulgaria. ${ }^{25}$

The work was supported by grants from the Wellcome Trust.

\section{References}

${ }^{1}$ Mahgoub A, Idle JR, Dring LG, Lancaster R, Smith RL. Polymorphic hydroxylation of debrisoquine in man. Lancet 1977;ii:584-6.

2 Evans DAP, Mahgoub A, Sloan TP, Idle JR, Smith RL. A family and population study of the genetic polymorphism of debrisoquine oxidation in a white British population. $J$ Med Genet 1980;17:102-5.

${ }^{3}$ Beckman R. The fate of biguanides in man. Ann NY Acad Sci 1968;148:820-32.

4 Oates NS, Shah RR, Idle JR, Smith RL. On the urinary disposition of phenformin and 4-hydroxy-phenformin and their rapid simultaneous measurement. J Pharm Pharmacol 1980; 32:731-2.

5 Oates NS, Shah RR, Idle JR, Smith RL. Genetic polymorphism of phenformin 4-hydroxylation in man. Clin Pharmacol Ther 1982;32:81-9. 
'Shah RR. Genetic susceptibility to adverse drug reactions. A clinical expression of deficient drug oxidation phenotype. MD thesis. University of London. 1983.

${ }^{7}$ Emery AEH. Methodology in medical genetics. Edinburgh: Churchill Livingstone. 1976.

× Iselius L, Evans DAP. Formal genetics of isoniazid metabolism in man. Clin Pharmacokinet 1983;8:541-4.

"Evans DAP, Harmer D, Downham DY, et al. The genetic control of sparteine and debrisoquine metabolism in man with new methods of analysing bimodal distributions. J Med Genet 1983:20:321-9.

${ }^{10}$ Luft D, Schmulling RM, Eggstein M. Lactic acidosis in biguanide-treated diabetics. A review of 330 cases. Diabetologia 1978;14:75-87.

$"$ Cohen RD. Drugs and lactic acidosis. Adverse Drug Reaction Bulletin 1978;70:248-51.

12 Nattrass M, Sizer K. Alberti KGMM. Correlation of plasma phenformin concentration with metabolic effects in normal subjects. Clin Sci 1980:58:153-5.

${ }^{13}$ Sussman KE, Alfrey A. Kirsch WM, Zweig P. Felig P. Messner F. Chronic lactic acidosis in an adult. A new syndrome associated with an altered redox state of certain NAD/NADH coupled reactions. Am J Med 1970);48:104-12.

${ }^{14}$ Shah RR, Oates NS, Idle JR, Smith RL. Genetic impairment of phenformin metabolism. Lancet 1980;i:1147.

15 Oates NS, Shah RR, Idle JR, Smith RL. Influence of oxidation polymorphism. on phenformin kinetics and dynamics. Clin Pharmacol Ther 1983:34:827-34.

16 Oates NS, Shah RR, Idle JR, Smith RL. Phenformin-induced lactic acidosis associated with impaired debrisoquine hydroxylation. Lancet 1981;i:837-8.

17 Wiholm BE, Alvan G, Bertilsson L, Säwe J, Sjöqvist F. Hydroxylation of debrisoquine in patients with lactic acidosis after phenformin. Lancet 1981;i:1098-9.
${ }^{18}$ Cooper RG. Evans DAP. Whibley EJ. Polymorphic hydroxylation of perhexiline maleate in man. J Med Genet 1984;21:27-33.

19 Dayer P. Balant L. Courvoisier F, et al. The genetic control of bufuralol metabolism in man. Eur J Drug Metab Pharmacokinet 1982;7:73-7.

20) Devonshire HW, Kong I, Cooper M, Sloan TP. Idle JR, Smith $\frac{\bar{\rho}}{\partial}$ RL. The contribution of genetically determined oxidation status to inter-individual variation in phenacetin disposition. Br J Clin Pharmacol 1983;16:157-66.

${ }^{21}$ Mellström B, Bertilsson L, Säwe J, Schulz HU. Sjöqvist F. E- $\vec{O}$ and Z-10-hydroxylation of nortriptyline: relationship to poly-. morphic debrisoquine hydroxylation. Clin Pharmacol Ther $\overrightarrow{\vec{\omega}}$ 1981:30:189-93.

22 Lennard MS, Silas JH, Freestone S, Ramsay LE, Tucker GT. Woods HF. Oxidation phenotype - a major determinant of metoprolol metabolism and response. $N$ Engl $J$ Med 1982;307:1558-60.

22 Woosley RL, Roder DM, Duff HJ, Carey EL, Wood AJJ, or Wilkinson GR. Co-inheritance of deficient oxidative metabolism $\omega$ of encainide and debrisoquine. Clin Res 1981;29:510A.

24 Idle JR, Mahgoub A. Sloan TP. Smith RL. Mbanefo CO. Bababunmi EA. Some observations on the oxidation phenotype status of Nigcrian patients presenting with cancer. Cancer Lett 1981:11:331-8.

25 Ritchie JC, Crothers MJ, Idle JR, et al. Evidence for an $\frac{9}{0}$ inherited metabolic susceptibility to endemic (Balkan) nephropathy. In: Strahinjic S, Stefanovic V, eds. Current research in $\underset{-}{-}$ endemic (Balkan) nephropathy. Nis: Nis University Press, 1983:23-7.

Correspondence and requests for reprints to Dr N SO Oates, Department of Pharmacology, St Mary's Hospital Medical School, London W2 1PG. 